\title{
Enhanced expression of transglutaminase 2 in anterior polar cataracts and its induction by TGF- $\beta$ in vitro
}

\author{
X H Wan, E H Lee, H J Koh, J Song, E K Kim, C Y Kim, J B Lee, S-Y Kim, K Yao, J H Lee
}

Br J Ophthalmol 2002;86:1293-1298

See end of article for authors' affiliations

Correspondence to: Joon H Lee, Department of Ophthalmology, Institute of Vision Research, and Protein Network Research Center, Yonsei University College of Medicine, 134 Shinchon-dong,

Sodaemun-gu, Seoul,

Korea 120-752;

joon613@yumc.yonsei.ac.kr

Accepted for publication 21 May 2002

\begin{abstract}
Background/aims: Transglutaminase activity has long been implicated in the cataract formation. However, the precise mechanism of how it is produced and involved in this process remains unclear. Here the authors sought to examine whether transglutaminase 2 (TGase 2) is expressed in lens epithelial cells from patients with anterior polar cataracts, to determine whether TGase 2 expression is induced by transforming growth factor (TGF- $\beta$ ) in cultured lens epithelial cells, and to determine whether TGase 2 participates in the crosslinking of fibronectin in lens epithelial cells in vitro.

Methods: Lens epithelial cells from anterior polar cataracts, nuclear cataracts, and non-cataractous clear lenses were examined for the expression of TGase 2 using reverse transcription-polymerase chain reaction, western blot analysis, and immunohistochemical analysis. The modulation of extracellular TGase 2 activity by TGF- $\beta$ was measured by the formation of fibronectin polymers and the incorporation of fluorescein cadaverine into extracellular matrix proteins. The effect of TGase 2 overexpression was analysed by immunofluorescence staining and western blot analysis of human lens epithelial (HLE) B-3 cells transiently transfected with TGase 2 gene.

Results: The expression of TGase 2 mRNA and its protein was markedly enhanced in lens epithelial cells from patients with anterior polar cataracts. Treatment of HLE B-3 cells with TGF- $\beta$ caused an increase in TGase 2 protein, its extracellular activity, and the crosslinking of fibronectin. Transient transfection of HLE B-3 cells with the TGase 2 gene led to the increased production of fibronectin monomers and polymers.

Conclusions: This study shows that TGase 2 is overexpressed in lens epithelial cells from anterior polar cataracts and that TGF- $\beta$ may be a causative factor in the induction of TGase 2 . The enhanced expression of TGase 2 might cause the accumulation and crosslinking of the extracellular matrix proteins and might play a part in anterior polar cataract development.
\end{abstract}

A nterior polar cataracts are formed by metaplasia of the lens epithelial cells beneath the anterior capsule of the lens. The lens epithelial cells of this region are transformed into myofibroblast-like cells attached to subcapsular plaques of abnormal extracellular matrix molecules. ${ }^{2}$ Transforming growth factor $\beta$ (TGF- $\beta$ ) has been reported to be a key modulator in this pathology. In rat lens cultures, TGF- $\beta$ induces distinct anterior opacities, and produces fibrotic plaques consisting of type I collagen and $\alpha$-smooth muscle actin. ${ }^{34}$ Moreover, transgenic mice expressing TGF- $\beta$ under the $\alpha$ A-crystallin promoter, develop opacities that resemble the plaques seen in human anterior polar cataracts. ${ }^{5}$ Analyses of lens epithelial cells from patients with anterior polar cataracts also indicate TGF- $\beta$ as a key factor in these cataractous changes. ${ }^{6}$ Extracellular proteins such as fibronectin, type I collagen, and TGF- $\beta$ inducible gene-h3 ( $\beta \mathrm{IG}-\mathrm{H} 3)$ have been detected in clinical specimens from patients with anterior polar cataracts. ${ }^{67}$

Transglutaminases (TGases) are a $\mathrm{Ca}^{2+}$ dependent family of enzymes that establish $\epsilon$-( $\gamma$-glutamyl) lysine crosslinkages and aid in the incorporation of polyamines and histamine into proteins via covalent bonding. ${ }^{89}$ The catalytic action of TGases results in the formation of an isopeptide bond that is highly resistant to proteolysis and denaturants. The TGase family is composed of several members, including plasma factor XIII, TGase 1 (keratinocyte TGase), TGase 2 (tissue TGase), TGase 3 (epidermal TGase), and TGase 4 (prostate TGase). Among them, TGase 2 has been most widely identified in many cell type ${ }^{10}$ and implicated in diverse physiological functions such as cell differentiation, ${ }^{11}$ wound healing, ${ }^{12}$ and apoptosis. ${ }^{13}$ TGase 2 can be involved in the crosslinking of both intracellular and extracellular proteins. For example, TGase 2 appears to be involved in the crosslinking of intracellular proteins in cells undergoing apoptotic cell death. ${ }^{13}$ TGase 2 can also be secreted onto the surface of the cells and play a key part in the crosslinking of extracellular matrix proteins. ${ }^{14-16}$

In this study, we sought to explore more detailed mechanisms implicated in the abnormal deposition of extracellular matrix molecules during anterior polar cataract formation. We speculated that TGase 2 could be an important pathogenic modulator in the matrix remodelling processes. To test this, we investigated the expression of TGase 2 in lens epithelial cells from cataract and non-cataract patients. We also explored whether TGF- $\beta$ increases the expression of TGase 2 and whether the overexpression of TGase 2 leads to the increased crosslinking of fibronectin in cultured lens epithelial cells.

\section{MATERIALS AND METHODS Human specimens}

Lens capsules attached to lens epithelial cells from patients were collected and classified by the same surgeon, according to a modified version of the Lens Opacities Classification Scale (LOCS)-III grading system. Non-cataractous clear lens capsules were obtained during clear lens extraction for the correction of high myopia. The ages of the patients with anterior polar cataract were $52-62$ years old and $40 \%$ were male. The ages of the patients with nuclear cataract were 60-72 years old and $45 \%$ were male. The ages of the control group were $34-40$ years old and 55\% were male. The anterior capsules were removed and placed immediately into TRIzol reagent (GibcoBRL, Gaithersburg, MD, USA) for RNA preparation, frozen, and stored at $-70^{\circ} \mathrm{C}$ for protein extraction, 
or fixed in neutral buffered formalin for immunohistochemical analysis. The number of specimens used in each experiment is described in the figure legends. The handling of human tissue samples complied with the tenets of the Declaration of Helsinki, and consent and proper approval were obtained before all experiments.

\section{Cell culture and treatment}

Human lens epithelial cell line HLE B-3 was kindly provided by Usha Andley (Washington University School of Medicine, St Louis, MO, USA), and maintained as described previously. ${ }^{17}$ The cultures were allowed to reach $75-80 \%$ confluence and supplemented with $10 \mathrm{ng} / \mathrm{ml}$ of TGF- $\beta 2$, or TGF- $\beta 1$ (PeproTech, Rocky Hill, NJ, USA) in serum free medium. At the indicated time points, the cells were collected for reverse transcription-polymerase chain reaction (RT-PCR) or western blot analysis.

\section{Immunohistochemical analysis of tissue sections}

Immunohistochemistry was performed as described previously. ${ }^{18}$ Briefly, anterior lens capsules with attached lens epithelial cells were fixed, paraffin embedded, and sectioned. The sections were then incubated with mouse anti-human TGase 2 antibody (CUB 7402, NeoMarkers, Fremont, CA, USA). The sections were then incubated in biotinylated goat anti-mouse IgG (Dako, Carpinteria, CA, USA) and streptavidin-horseradish peroxidase (HRP), and visualised according to the manufacturer's instructions using a detection kit (LSAB/DAB + System, Dako). The immunolabelled sections were counterstained with Meyer's haematoxylin and examined with a light microscope. Control experiments were performed with identical procedures with normal mouse IgG in place of primary antibody. All experiments were replicated at least twice.

\section{RNA isolation and RT-PCR}

Total cellular RNA was extracted from lens epithelial cells attached to the anterior capsules of human lenses or cultured HLE B-3 cells using TRIzol reagent, according to the manufacturer's instructions. Samples of RNA ( $1 \mu \mathrm{g}$ of total RNA) was reverse transcribed and amplified with gene specific primers using a ThermoScript RT-PCR System kit (GibcoBRL). DNA size markers were run in parallel to validate the predicted sizes of the amplified bands (MBI Fermentas, Hanover, MD, USA). The primer sequences specific for the genes examined and expected product sizes were as follows: 5'-GATTGGGAA CTGGTCTGGTG-3' (sense), 5'-CTGAGCCTTCTGGGTGCTTA-3' (antisense), for TGase 1 (638 bp), 5'-CGAACCACCTGAA CAAACTG-3' (sense), 5' -ATCTCCACCGTCTTCTGCTC-3' (antisense), for TGase 2 ( 538 bp), 5' -ATCCCATCACCATCTTCCAG-3' (sense), 5'-CCTGCTTCACCACCTTCTTG-3' (antisense), for glyceraldehyde-3-phosphate dehydrogenase (GAPDH; 579 bp). The primers were synthesised by GibcoBRL.

\section{Western blot analysis}

Total cell lysates were isolated from the lens epithelial cells of human lens capsules or cultured HLE B-3 cells using lysis buffer (25 mM HEPES, pH 7.5, 0.3 M NaCl, $1.5 \mathrm{mM} \mathrm{MgCl}, 0.2$ mM EDTA, 0.05\% Triton X-100, 0.5 mM DTT, $0.4 \mathrm{mM}$ PMSF (Sigma, St Louis, MO), $2 \mu \mathrm{g} / \mathrm{ml}$ leupeptin (Sigma), and 2 $\mu \mathrm{g} / \mathrm{ml}$ aprotinin (Sigma)). After centrifugation for 10 minutes at $12000 \mathrm{~g}$, the supernatant proteins ( $5 \mu \mathrm{g} / \mathrm{lane}$ ) were subjected to SDS-polyacrylamide gel electrophoresis and transferred to nitrocellulose membranes (Hybond, Amersham, Piscataway, NJ, USA). To aid transfer of crosslinked proteins, $75 \mu \mathrm{g} / \mathrm{ml}$ of pronase (Sigma) was added into the transfer buffer, and the blotting membrane was presoaked in this buffer before transfer. The membranes were blocked and incubated with mouse anti-TGase 2 antibody (NeoMarkers), mouse anti-fibronectin antibody (Sigma), or mouse anti- $\beta$ actin antibody (Sigma) at 1:1000 dilution. These blots were then reacted with a HRP conjugated anti-mouse secondary antibody (Amersham). A stripping and reprobing of the membrane was performed as described in the manufacturer's instructions (Amersham). Immunoreactive proteins were visualised using ECL detection reagents (Amersham) on autoradiographic films.

\section{Detection of extracellular TGase 2 activity}

An in situ TGase2 activity assay was performed as previously described..$^{19}{ }^{20}$ Briefly, HLE B-3 cells were seeded into four well glass chamber slides (Nunc, Naperville, IL, USA). After reaching $60-65 \%$ confluence, cells were washed and incubated in the presence or absence of $10 \mathrm{ng} / \mathrm{ml}$ of TGF- $\beta 2$ or TGF- $\beta 1$ for 72 hours. Then, $0.5 \mathrm{mM}$ fluorescein cadaverine (Molecular Probes, Eugene, OR, USA) was added to the cell culture and incubated for 15 hours. To inhibit TGase 2 activity, $0.1 \mathrm{mM}$ monodansylcadaverine (Sigma) was added to the cultures with TGF- $\beta 2$. After incubation the cells were washed, fixed in methanol at $-20^{\circ} \mathrm{C}$, and mounted. In double staining experiments, after staining with fluorescein cadaverine and fixing, cells were blocked with 3\% bovine serum albumin (BSA) in phosphate buffered saline (PBS), incubated with mouse anti-fibronectin antibody (Sigma) diluted 1:50 in blocking buffer for 15 hours at $4^{\circ} \mathrm{C}$, and then incubated with rhodamine conjugated (TRITC) anti-mouse IgG (Sigma) diluted 1:30 in blocking buffer, for 2 hours at room temperature. Cells were viewed using a confocal laser microscope (Leica CLSM, Swiss) equipped with an argon krypton laser set at $488 \mathrm{~nm}$ and $560 \mathrm{~nm}$ for fluorescein and rhodamine excitation.

\section{Cloning of TGase 2 gene}

TGase 2 cDNA was obtained by nested polymerase chain reaction (PCR) amplification using a human fibroblast cDNA library (Clontech, Palo Alto, CA, USA). The first PCR was performed with PCR primers located between 72 and 2388 bp of the human TGase 2 gene, where the $3^{\prime}$ primer is close to the poly (A) tail: 5'-CCTCCTTAAAGCATAAATCTC-3' (sense), 5'-TTAGGCGGGGCCAATGATGAC-3' (antisense). The PCR product was purified using a PCR purification kit (Qia quick, Qiagen, Valencia, CA, USA), and used as template for the second PCR. The construct of human TGase 2 gene was designed to be inserted into the pIND (SP1) expression vector (Invitrogen, San Diego, CA, USA). The second set of PCR primers was designed with an extension of extranucleotides containing the restriction enzyme sites of EcoRI at the 5' end and XhoI at the 3' end: 5' -agtaaaGAATTCATGGCCGAGCTGGTCTTAGAGAGGT GTGATCTG-3' (sense, EcoRI), 5'-gaatcaGAGCTCTTATCAAATG ATGACATTCCGGAAGCCCTT-3' (antisense, XhoI). The PCR conditions used were: $95^{\circ} \mathrm{C}$ for 4 minutes, and 30 cycles of $95^{\circ} \mathrm{C}$ for 30 seconds, $55^{\circ} \mathrm{C}$ for 30 seconds, and $72^{\circ} \mathrm{C}$ for $\mathrm{l}$ minute. The PCR products were purified using a PCR purification kit, and digested with EcoRI and XhoI. The full length human TGase 2 gene was ligated into the expression vector, transformed, and sequenced to verify the amplification efficacy.

\section{Immunofluorescence staining of extracellular TGase 2 and fibronectin in cells transiently transfected with TGase 2 gene}

For transient transfection of HLE B-3 cells with TGase 2 gene, TGase 2 cDNA in pIND was digested with EcoRI and XhoI, and then subcloned into the eukaryotic expression vector pcDNA 3.1(+) (Invitrogen) at EcoRI-XhoI sites. HLE B-3 cells were transfected with pcDNA 3.1(+)-TGase 2 or pcDNA $3.1(+)$ as a control, using the FuGENE 6 transfection reagent (Roche Diagnostics, Indianapolis, IN, USA) as described in the manufacturer's instruction. Briefly, $1 \times 10^{5}$ cells were plated per well of a six well culture dish and transfected with $1 \mu \mathrm{g}$ of pcDNA $3.1(+)$-TGase 2 or pcDNA 3.1(+). After 72 hours, cells were 


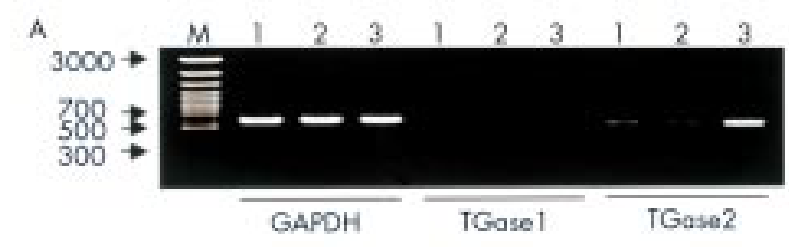

B
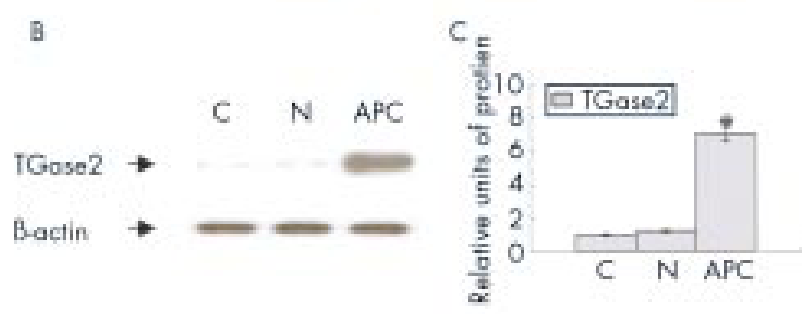

D
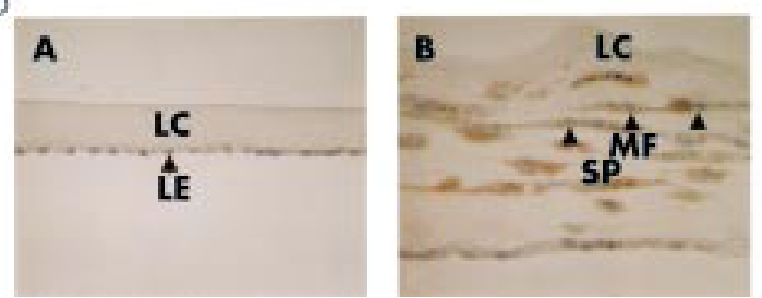

Figure 1 Enhanced expression of TGase 2 in human anterior polar cataracts. (A) Total cellular RNA was isolated from lens epithelial cells of patients with nuclear cataracts (lane 1), non-cataractous clear lenses (lane 2), and anterior polar cataracts (lane 3). The levels of mRNAs for GAPDH, TGase 1, and TGase 2 were examined by RT-PCR. The data shown are from one of three independent assays that produced similar results. $M=$ molecular size standards (in base pairs). (B) Cell lysates were prepared from lens epithelial cells attached to the anterior capsules, and then the levels of TGase 2 proteins were assessed by western blot analysis. After separating proteins by SDS-PAGE, the whole gel was immunoprobed. $\beta$-actin was used as the loading control indicator. $C=$ nuclear cataracts (lane 1); $N=$ non-cataractous clear lenses (lane 2); $A P C=$ anterior polar cataracts (lane 3). (C) Proteins were quantified using a bioimaging analyser (Bio-Rad Imaging System, Bio-Rad, Hercules, CA, USA), and expressed in arbitrary units. Each displayed value was normalised against the density of the respective band of $\beta$-actin, and the displayed values in this graph represents the mean value (SD) of samples from seven patients ( $\left.{ }^{*} p<0.05\right)$. (D) Anterior lens capsules with attached lens epithelial cells from patients with anterior polar cataracts (panel B), and nuclear cataracts (panel A) were assayed immunohistochemically for TGase2 expression (brown colour) (original magnification, $\times 400$ ). The capsules of anterior polar cataracts were thinner than those in nuclear cataracts, as previously reported. ${ }^{7}$ The data presented were from one of six independent assays that produced similar results. $L C=$ lens capsule; $L E=$ lens epithelial cells (arrow); SP = subcapsular plaque; MF = myofibroblastlike lens epithelial cells (arrowheads).

either immunofluorescence stained or collected for western blot analysis. The double immunofluorescence staining procedure was performed as described above.

\section{RESULTS}

Increased expression of TGase 2 in lens epithelial cells from patients with anterior polar cataracts

To determine whether TGase 2 expression may be implicated in human anterior polar cataracts, we compared the levels of TGase 2 mRNA in lens epithelial cells from anterior polar cataracts with those from nuclear cataracts and noncataractous clear lenses. As shown in Figure 1A, the expression of TGase 2 mRNA was markedly enhanced in the lens epithelial cells of anterior polar cataracts. Meanwhile, the expression of TGase 1, which has been detected in the corneal epithelium, ${ }^{21}$ was not detectable in any specimen. The amount of GAPDH product, an internal housekeeping control for PCR amplification, was similar in all specimens.
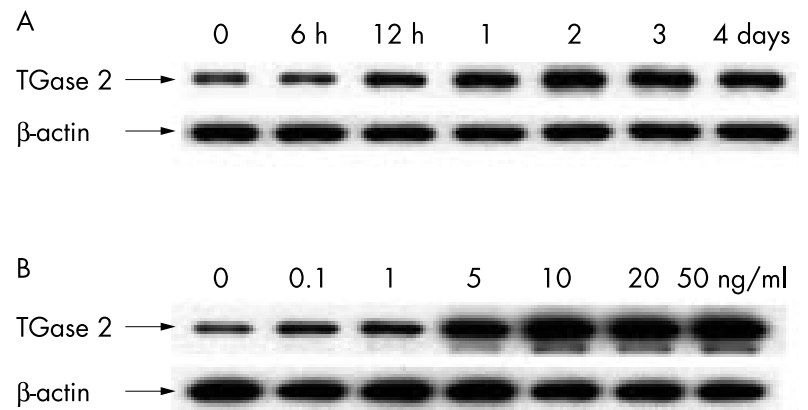

Figure 2 Enhanced expression of TGase 2 by TGF- $\beta 2$ in cultured HLE B-3 cells. Cells were seeded in $100 \mathrm{~mm}$ culture dishes coated with collagen type IV $\left(10 \mu \mathrm{g} / \mathrm{ml}\right.$, Sigma) at $1.0 \times 10^{6} \mathrm{cell} / \mathrm{s} / \mathrm{dish}$. Time and dose responses of the induction of TGase 2 in lens epithelial cells treated with TGF- $\beta 2$. (A) Time response: cells incubated with $10 \mathrm{ng} / \mathrm{ml}$ of TGF- $\beta 2$ in serum free medium were harvested at the indicated time intervals and subjected to western blot analysis. (B) Dose response: after incubation with various concentrations of TGF- $\beta 2$ for 48 hours, cells were extracted for western blot analysis. Results were representative of three repeated experiments.

To confirm the expression of the corresponding proteins, we extracted cell lysates from the lens epithelial cells attached to the anterior capsules and performed western blot analysis. As shown in Figure $1 \mathrm{~B}$, a single band for TGase 2 at approximately $84 \mathrm{kDa}$ was detected. The results correlated with the RT-PCR data, and demonstrated a significantly higher expression of TGase 2 in lens epithelial cells from anterior polar cataracts than that in lens epithelial cells from nuclear cataracts or non-cataractous clear lenses. Quantification of each band by densitometric scanning using seven specimens for each type of patient also showed that there was a significantly increased expression of TGase 2 in lens epithelial cells from the patients with anterior polar cataracts (Fig lC).

We also tested TGase 2 expression in clinical samples using immunohistochemical analysis. As shown in Figure 1D, in the subcapsular plaques of the anterior polar cataracts, lens epithelial cells surrounded by extracellular matrices were positive for TGase 2 (Fig 1D, panel B). By comparison, TGase 2 was barely detectable in lens epithelial cells obtained from nuclear cataracts (Fig 1D, panel A) or non-cataractous clear lenses (data not shown). Sections incubated without primary antibody showed no reactivity (data not shown). These results were in agreement with the RT-PCR and western blot data.

\section{Enhanced expression of TGase 2 in cultured lens epithelial cells treated with TGF- $\beta$}

TGF- $\beta$ has shown to be a key modulator in anterior polar cataract formation. ${ }^{4}$ We, therefore, examined whether TGF- $\beta 2$ can increase the expression of TGase 2 in lens epithelial cells. As shown in Figure 2A, the expression of TGase 2 protein was substantially increased in a time dependent manner after treating HLE B-3 cells with $10 \mathrm{ng} / \mathrm{ml}$ of TGF- $\beta 2$. The increased levels were maintained for 3-4 days. Two days after treatment with different concentrations of TGF- $\beta 2$, the expression of TGase 2 protein was detected even at the concentration as low as $0.1 \mathrm{ng} / \mathrm{ml}$, and increased in a dose dependent manner (Fig 2B). A plateau was reached at $10 \mathrm{ng} / \mathrm{ml}$. The expression of TGase 2 mRNA was also increased in time and dose dependent manners in cells treated with TGF- $\beta 2$ (data not shown). Similar effects were observed after treatment of HLE B-3 cells with TGF- $\beta 1$ (data not shown).

Increased extracellular TGase 2 activity by TGF- $\beta 2$ and its inhibition by monodansylcadaverine

In previous reports, TGase 2 activity was visualised in situ by incorporation of a specific substrate, fluorescein cadavarine. ${ }^{192}$ Fluorescein cadaverine is believed to act as a 

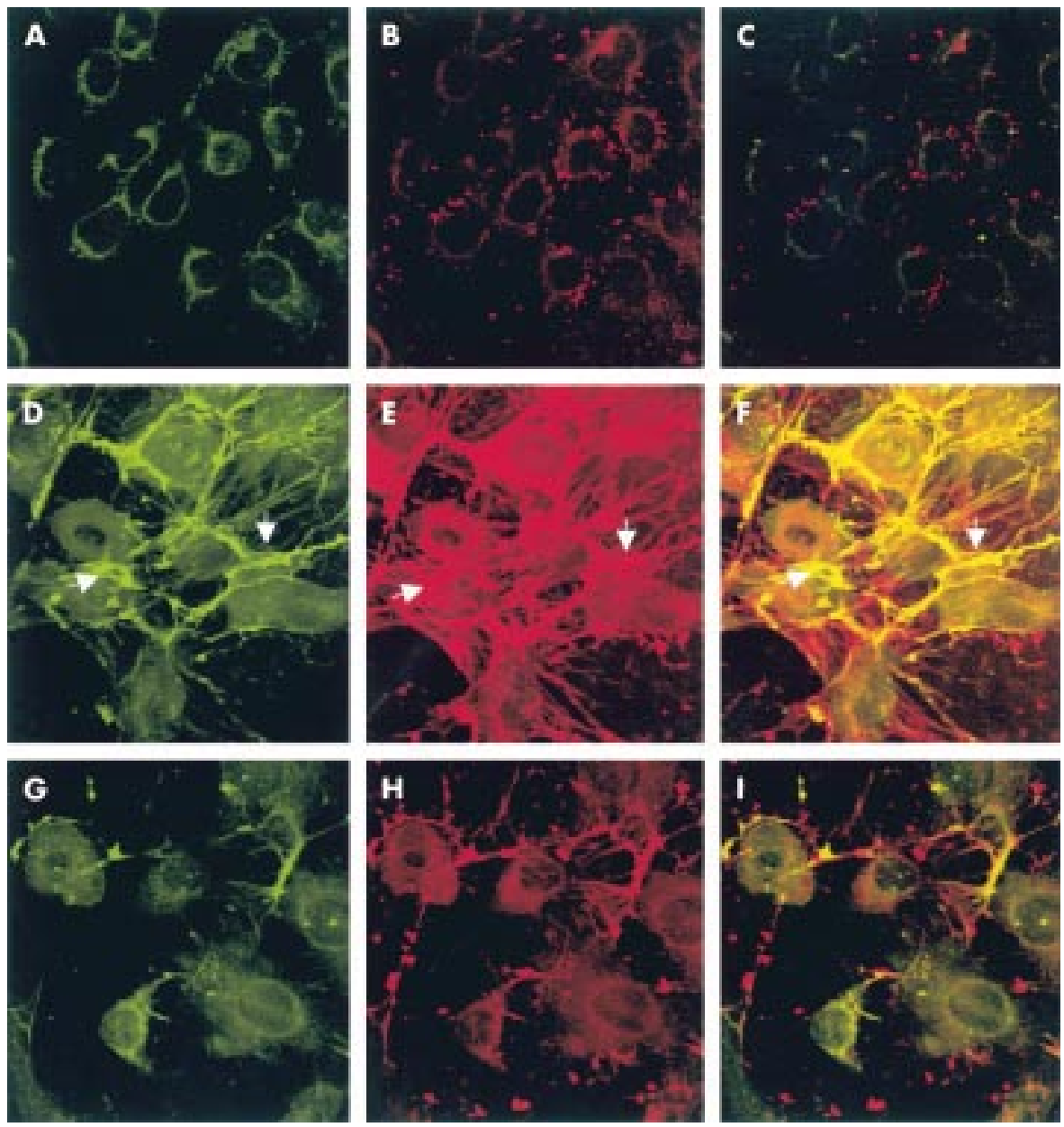

Figure 3 Double immunofluorescence analysis of in situ TGase 2 activity, as shown by TGase 2 mediated fluorescein cadaverine (green) incorporation and fibronectin (red) fibril formation (original magnification $\times 800$ ). The co-localisation of fluorescein cadaverine and fibronectin resulted in a bright yellow mixed colour by double filter analysis. In non-treated control cells, fluorescein cadaverine (A) and fibronectin (B) were sparse, and only very small yellow spots were observed between the cells after pictures were superimposed (C). In TGF- $\beta$ treated cells, the staining for fluorescein cadaverine $(D)$ and fibronectin $(E)$ were markedly augmented and prominent yellow spots were visible between the cells (F), indicating an increase in the co-localisation of fluorescein cadaverine and fibronectin. After treating the TGF- $\beta 2$ treated cells with monodansylcadaverine, the staining of fluorescein cadaverine $(G)$, fibronectin fibrils $(H)$, and co-localisation (I) was markedly decreased. Arrows point to areas of high TGase 2 activity, where fibronectin fibrils are also co-localised.

competitive primary amine to the peptide bound $\epsilon$-amino lysine group, and becomes incorporated into endogenous $\gamma$-glutamyl residues if active TGase 2 is present. In order to determine whether the increased crosslinking of fibronectin by TGF- $\beta$ may be correlated with increase in TGase 2 activity, HLE B-3 cells treated with or without TGF- $\beta 2$ were cultured in the presence of fluorescein cadaverine and examined by confocal laser microscopy.

As shown in Figure 3, after treatment with TGF- $\beta 2$, cells exhibited a large number of fluorescein cadavarine punctuate patches on the surface of the cells, indicating enhanced TGase 2 activity (Fig 3D). A much weaker staining pattern was observed in non-treated control cells (Fig 3A). Antibody to fibronectin revealed very few fibronectin fibrils in non-treated control cells (Fig 3B). Abundant fibrils were observed on the surface of the cells treated with TGF- $\beta 2$ (Fig 3E). Superimposed images depicted the increased co-localisation of fluorescein cadaverine and fibronectin in cells treated with TGF- $\beta 2$ (Fig 3F) compared to non-treated control cells (Fig 3C). This indicated that TGase 2 might be directly involved in the crosslinking of fibronectin. The addition of monodansylcadaverine, a selective irreversible inhibitor for TGase 2, to the cells treated with TGF- $\beta 2$, led to a considerable reduction in incorporation of fluorescein cadaverine (Fig 3G), fibril formation of fibronectin (Fig 3H), and their co-localisation (Fig 3I).
Similar effects were observed after treating cells with TGF- $\beta 1$ (data not shown).

Enhanced expression and crosslinking of fibronectin in HLE B-3 cells transiently transfected with TGase 2 gene Results shown in Figure 3 indicated that TGase 2 might be directly involved in the crosslinking of fibronectin in response to TGF- $\beta$. To further investigate this possibility, TGase 2 gene was transiently overexpressed in HLE B-3 cells. Double immunofluorescence staining procedure for cadaverine and fibronectin labelling was performed 72 hours after cells were transfected with the human TGase 2 gene. As shown in Figure $4 \mathrm{~A}$, extracellular activity of TGase 2 protein was clearly increased in cells transfected with TGase 2 gene (Fig 4A, panel $\mathrm{D})$, but barely visible in control cells transfected with the vector alone (Fig 4A, panel A). Moreover, when these cells were co-stained with fibronectin antibody, cells transfected with TGase 2 gene showed a significantly enhanced staining (Fig 4A, panel E) compared with control cells (Fig 4A, panel B). Superimposed images depicted the increased co-localisation of fluorescein cadaverine and fibronectin in cells transfected with TGase 2 gene (Fig 4A, panel F) compared to control cells transfected with the vector alone (Fig 4A, panel C). This was further confirmed by western blot analysis. As shown in Figure $4 \mathrm{~B}$ increased amounts of fibronectin monomers and polymers were detected from the lysates of cells transfected with 

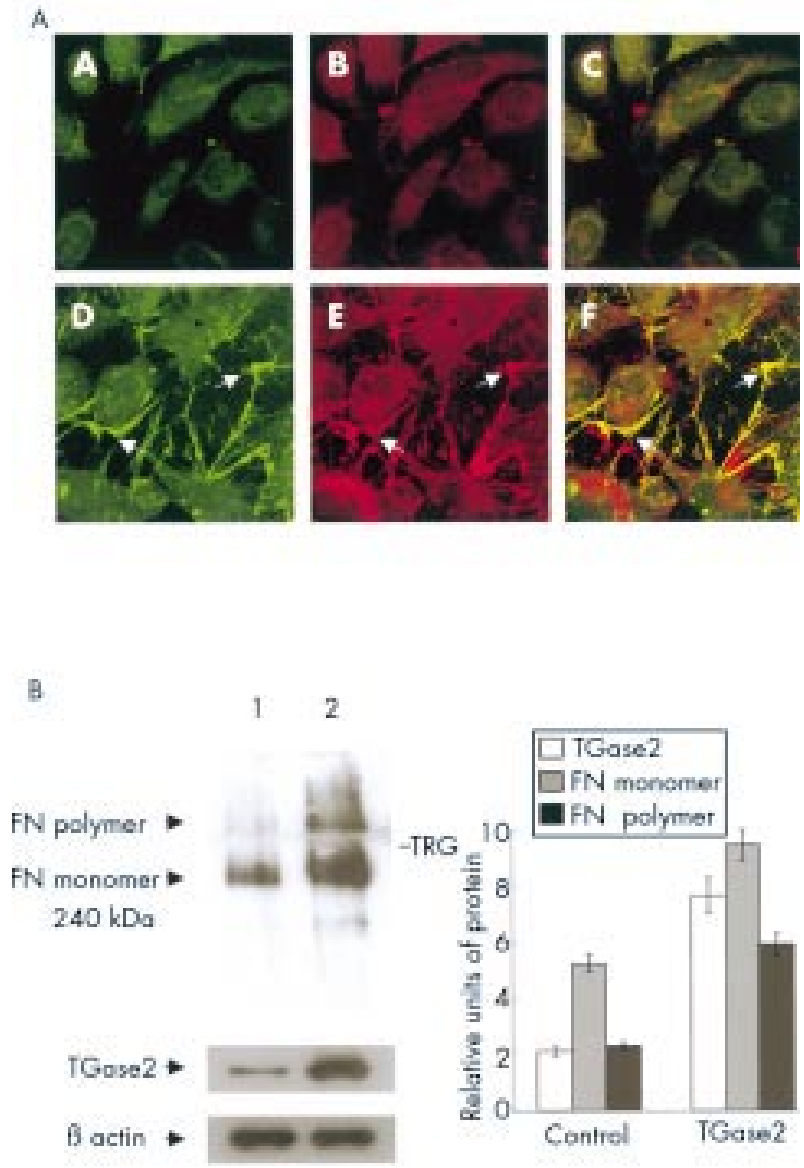

Figure 4 Enhanced crosslinking of fibronectin in TGase 2 overexpressed cells. (A) Immunofluorescence localisation of in situ TGase 2 activity (green), fibronectin (red) fibrils, and the co-localisation of TGase 2 activity and fibronectin fibrils (yellow) in HLE B-3 cells transiently transfected with the TGase 2 gene loriginal magnification $\times 800$ ). Panels $A, B$, and $C$ vector transfected control cells; panels D, E, and F, TGase 2 transfected cells. Arrows point to areas of high TGase 2 activity, where fibronectin fibrils are also co-localised. (B) Western blot analysis of fibronectin and TGase 2 in the lysates of HLE B-3 cells. The lysates from vector transfected control cells (lane 1) and cells transiently transfected with the TGase 2 gene (lane 2) were extracted and fractionated by SDS-PAGE. The whole gel, including both resolving and stacking gel, was immunoprobed with fibronectin and TGase 2. Results were representative of three repeated experiments. TRG = top of resolving gel. Proteins were quantified as described before. The displayed values in the bar graph represent the mean value $(S D)$ of three independent experiments.

TGase 2 gene (lane 2) compared to those of control cells (lane 1). This indicated that the increased expression of fibronectin monomers and the crosslinking of fibronectin were coincident with the overexpression of TGase 2 in lens epithelial cells.

\section{DISCUSSION}

The aberrant accumulation of extracellular matrix proteins, such as fibronectin and type I collagen, has been previously demonstrated in anterior polar cataracts. TGF- $\beta$ has been consistently shown as a prime factor implicated in this pathological process. ${ }^{4-6}$ However, the precise mechanism as to how TGF- $\beta$ establishes the irreversible abnormal extracellular matrix deposits in anterior polar cataracts remains to be explored.

TGase 2 has been detected in various ocular tissues, including the ciliary body, iris, conjunctiva, and trabecular meshwork, where it might stabilise structural proteins and extracellular matrix-cell interactions. ${ }^{21-23}$ In the lens, the presence of TGase 2 in non-cataractous lens epithelial cells has been reported previously. ${ }^{21}{ }^{22}$ Our RT-PCR and western blot analyses showed limited expression of TGase 2 in noncataractous lens epithelial cells. TGase has also been implicated in cataract formation. In senile cataracts, considerably higher TGase activity was found in the lens cortex, ${ }^{24}{ }^{25}$ with $\beta$-crystallin and vimentin having been identified as possible substrates. ${ }^{26-28}$ Previous studies have also demonstrated that TGase 2 can bind several extracellular matrix proteins in other cell types. ${ }^{29-32}$ Martinez et al reported that cell surface TGase 2 can mediate the crosslinking of fibronectin in human umbilical vein endothelial cells. ${ }^{33}$ In this study, we demonstrated that the expression of TGase 2 was significantly increased in lens epithelial cells from anterior polar cataracts. This suggests that overexpression of TGase 2 may be involved in the crosslinking of extracellular matrix proteins, such as fibronectin, seen in anterior polar cataracts.

TGF- $\beta$ has been reported to induce the expression of TGase 2 in various cells including rabbit tracheal epithelial cells, human epidermal keratinocytes, and rat hepatoma cell lines. ${ }^{34-36}$ Notably, in the eye TGF- $\beta$ induces the expression of TGase 2 and the crosslinking of fibronectin in human trabecular meshwork. ${ }^{23}$ We showed that TGF- $\beta$ induced the overexpression of TGase 2 and the crosslinking of fibronectin in human lens epithelial cells. This result adds TGase 2 to the group of genes that is increased by TGF- $\beta$ in lens epithelial cells. We also observed that TGF- $\beta$ induced crosslinking of fibronectin was significantly reduced by TGase 2 inhibitor and that an increased crosslinking of fibronectin was observed in lens epithelial cells transfected with TGase 2 gene. These results suggest that TGase 2 mediates the TGF- $\beta$ induced formation of fibronectin polymers and that the overexpression of TGF- $\beta$ and TGase 2, and the aberrant accumulation of extracellular matrix proteins in anterior polar cataracts are pathologically coordinated.

Secreted TGF- $\beta$ is non-covalently associated with latency associated peptide (LAP), in a biologically inactive form. ${ }^{37}$ This complex is secreted as part of a larger latent complex in which latent binding protein (LTBP) is linked to LAP via disulphide bonds.$^{38}$ Recent reports suggested that TGase 2 might enhance the conversion of latent TGF- $\beta$ to active TGF- $\beta$. This conversion may in turn stimulate the expression of TGF- $\beta$ mRNA by an autocrine mechanism. ${ }^{39-41}$ It has also been proposed that matrix association of LTBP-1, a critical step in the activation of latent TGF- $\beta$, is TGase 2 dependent. ${ }^{39-41}$ Interestingly, our results showed that transient transfection of lens epithelial cells with TGase 2 gene stimulated increased levels of fibronectin polymers and increased expression of fibronectin monomers (Fig 4). According to our preliminary data, HLE B-3 cells in the absence of any stimulators exhibited substantial expression of TGF- $\beta$ mRNA (data not shown). Taken together, the results imply that TGase 2 might function to convert latent TGF- $\beta$ to active TGF- $\beta$, which could further augment fibronectin expression and accelerate development of fibrotic plaques. In support of this notion, the elevated level of TGF- $\beta$ mRNA has previously been documented in lens epithelial cells from patients with anterior polar cataracts. ${ }^{6}$ Further investigations are needed to test whether TGase 2 increases the amount of active TGF- $\beta$ in lens epithelial cells.

In conclusion, we report for the first time that lens epithelial cells of human anterior polar cataracts overexpress TGase 2. The elevation of TGase 2 might be important in covalent crosslinking of extracellular matrix protein such as fibronectin, which might render them less accessible to matrix degrading proteases or other degradative agents. This could reduce the turnover of these matrices and contribute to the persistence of subcapsular plaques.

\section{ACKNOWLEDGEMENTS}

The authors thank Usha Andley for HLE B-3 cells and David Beebe for valuable comments on this manuscript. This work was supported by a 
grant from the Ministry of Science and Technology of Korea/the Korea Science and Engineering Foundation through Protein Network Research Center at Yonsei University.

Commercial relations policy: None.

\section{Authors' affiliations}

X H Wan, H J Koh, J Song, E K Kim, C Y Kim, J B Lee, J H Lee, Department of Ophthalmology, Institute of Vision Research, Yonsei University College of Medicine, Seoul, Korea

J H Lee, Protein Network Research Center, Yonsei University College of Medicine, Seoul, Korea

E H Lee, Graduate School of East-West Medical Science, Kyung Hee University, Yong-In, Korea

X H Wan, K Yao, Department of Ophthalmology, Second Hospital, Zhejiang University College of Medicine, Hangzhou, China S-Y Kim, Department of Neuroscience, Weil Medical College of Cornel University, Burke Medical Research Institute, White Plains, NY, USA

\section{REFERENCES}

1 Novotny GE, Pau H. Myofibroblast-like cells in human anterior capsular cataract. Virchows Arch 1984;404:393-401.

2 Pau H, Novotny GE. Ultrastructural investigations on anterior capsular cataract. Cellular elements and their relationship to basement membrane and collagen synthesis. Graefes Arch Clin Exp Ophthalmol 1985;223:41-6

3 Hales AM, Schulz MW, Chamberlain CG, et al. TGF-beta 1 induces lens cells to accumulate alpha-smooth muscle actin, a marker for subcapsular cataracts. Curr Eye Res 1994;13:885-90.

4 Hales AM, Chamberlain CG, McAvoy JW. Cataract induction in lenses cultured with transforming growth factor-beta. Invest Ophthalmol Vis Sci 1995;36:1709-13

5 Srinivasan Y, Lovicu FJ, Overbeek PA. Lens-specific expression of transforming growth factor betal in transgenic mice causes anterior subcapsular cataracts. I Clin Invest 1998:101:625-34.

6 Lee EH, Joo CK. Role of transforming growth factor-beta in transdifferentiation and fibrosis of lens epithelial cells. Invest Ophthalmol Vis Sci 1999;40:2025-32.

7 Lee EH, Seomun Y, Hwang KH, et al. Overexpression of the transforming growth factor-beta-inducible gene betaig-h3 in anterior polar cataracts. Invest Ophthalmol Vis Sci 2000;41:1840-5.

8 Folk JE. Transglutaminases. Annu Rev Biochem 1980;49:517-31.

9 Greenberg CS, Birckbichler PJ, Rice RH. Transglutaminases: multifunctional cross-linking enzymes that stabilize tissues. FASEB J 1991:5:3071-7.

10 Thomazy V, Fesus L. Differential expression of tissue transglutaminase in human cells. An immunohistochemical study. Cell Tissue Res 1989;255:215-24

11 Suedhoff T, Birckbichler PJ, Lee KN, et al. Differential expression of transglutaminase in human erythroleukemia cells in response to retinoic acid. Cancer Res 1990;50:7830-4.

12 Upchurch HF, Conway E, Patterson MKJ, et al. Localization of cellular transglutaminase on the extracellular matrix after wounding characteristics of the matrix bound enzyme. J Cell Physiol $1991 ; 149: 375-82$

13 Fesus L, Davies PJ, Piacentini M. Apoptosis: molecular mechanisms in programmed cell death. Eur J Cell Biol 1991;56:170-7.

14 Aeschlimann D, Paulsson M. Cross-linking of laminin-nidogen complexes by tissue transglutaminase. A novel mechanism for basement membrane stabilization. J Biol Chem 1991;266:15308-17.

15 Aeschlimann D, Kaupp O, Paulsson M. Transglutaminase-catalyzed matrix cross-linking in differentiating cartilage: identification of osteonectin as a major glutaminyl substrate. J Cell Biol 1995; 129:881-92.

16 Raghunath M, Hopfner B, Aeschlimann D, et al. Cross-linking of the dermo-epidermal junction of skin regenerating from keratinocyte autografts. Anchoring fibrils are a target for tissue transglutaminase. $J$ Clin Invest 1996;98:1174-84

17 Andley UP, Rhim JS, Chylack LTJ, et al. Propagation and immortalization of human lens epithelial cells in culture. Invest Ophthalmol Vis Sci 1994;35:3094-102.
18 Oppermann B, Zhang W, Magabo K, et al. Identification and spatial analysis of metallothioneins expressed by the adult human lens. Invest Ophthalmol Vis Sci 2001;42:188-93.

19 Verderio E, Nicholas B, Gross S, et al. Regulated expression of tissue transglutaminase in Swiss 3T3 fibroblasts: effects on the processing of fibronectin, cell attachment, and cell death. Exp Cell Res 1998;239:119-38.

20 Lajemi $M$, Demignot S, Borge $L$, et al. The use of fluoresceincadaverine for detecting amine acceptor protein substrates accessible to active transglutaminase in living cells. Histochem J 1997;29:593-606.

21 Welge-Lussen $U$, May CA, Lutien-Drecoll E. Induction of tissue transglutaminase in the trabecular meshwork by TGF-betal and TGF-beta2. Invest Ophthalmol Vis Sci 2000;41:2229-38.

22 Raghunath M, Cankay R, Kubitscheck U, et al. Transglutaminase activity in the eye: cross-linking in epithelia and connective tissue structures. Invest Ophthalmol Vis Sci 1999;40:2780-7.

23 Hidasi V, Adany R, Muszbek L. Localization of transglutaminase in human lenses. J Histochem Cytochem 1995;43:1173-7.

24 Lorand L, Conrad SM, Velasco PT. Formation of a 55000-weight cross-linked beta crystallin dimer in the $\mathrm{Ca}^{2+}$-treated lens. A model for cataract. Biochemistry 1985;24:1525-31.

25 Lorand L, Hsu LK, Siefring GE, et al. Lens transglutaminase and cataract formation. Proc Natl Acad Sci USA 1981;78:1356-60.

26 Lorand L, Velasco PT, Murthy SN, et al. Isolation of transglutaminase-reactive sequences from complex biological systems: a prominent lysine donor sequence in bovine lens. Proc Natl Acad Sci USA 1992;89:11161-3

27 Groenen PJ, Grootjans JJ, Lubsen NH, et al. Lys-17 is the amine-donor substrate site for transglutaminase in beta A3-crystallin. J Biol Chem 1994;269:831-3.

28 Clement SV, P.T., Murthy SN, Wilson JH, et al. The intermediate filament protein, vimentin, in the lens is a target for cross-linking by transglutaminase. J Biol Chem 1998;273:7604-9.

29 Bowness JM, Folk JE, Timpl R. Identification of a substrate site for liver transglutaminase on the aminopropeptide of type III collagen. J Biol Chem 1987;262: 1022-4

30 Achyuthan KE, Mary A, Greenberg CS. The binding sites on fibrin(ogen) for guinea pig liver transglutaminase are similar to those of blood coagulation factor XIII. Characterization of the binding of liver transglutaminase to fibrin. J Biol Chem 1988;263:14296-301.

31 Lorand L, Dailey JE, Turner PM. Fibronectin as a carrier for the transglutaminase from human erythrocytes. Proc Natl Acad Sci USA 1988;85: 1057-9.

32 Turner PM, Lorand L. Complexation of fibronectin with tissue transglutaminase. Biochemistry 1989;28:628-35.

33 Martinez J, Chalupowicz DG, Roush RK, et al. Transglutaminase-mediated processing of fibronectin by endothelial cell monolayers. Biochemistry 1994;33:2538-45.

34 Jetten AM, Shirley JE, Stoner G. Regulation of proliferation and differentiation of respiratory tract epithelial cells by TGF beta. Exp Cell Res 1986;167:539-49

35 George MD, Vollberg TM, Floyd EE, et al. Regulation of transglutaminase type II by transforming growth factor-beta 1 in normal and transformed human epidermal keratinocytes. J Biol Chem 1990;265: 11098-104.

36 Fukuda K, Kojiro M, Chiu JF. Differential regulation of tissue transglutaminase in rat hepatoma cell lines McA-RH7777 and McA-RH8994: relation to growth rate and cell death. J Cell Biochem 1994;54:67-77.

37 Gentry LE, Webb NR, Lim GJ, et al. Type 1 transforming growth factor beta: amplified expression and secretion of mature and precursor polypeptides in Chinese hamster ovary cells. Mol Cell Biol 1987;7:3418-27.

38 Miyazono K, Ichijo $\mathrm{H}$, Heldin $\mathrm{CH}$. Transforming growth factor-beta: latent forms, binding proteins and receptors. Growth Factors 1993;8: 11-22

39 Kojima S, Nara K, Rifkin DB. Requirement for transglutaminase in the activation of latent transforming growth factor-beta in bovine endothelial cells. J Cell Biol 1993;121:439-48.

40 Kojima S, Vernooy R, Moscatelli D, et al. Lipopolysaccharide inhibits activation of latent transforming growth factor-beta in bovine endothelia cells. J Cell Physiol 1995;163:2 10-19.

41 Nunes I, Shapiro RL, Rifkin DB. Characterization of latent TGF-beta activation by murine peritoneal macrophages. J Immunol $1995 ; 155: 1450-9$. 